\title{
THE SOCIAL VALIDITY OF TELEPRACTICE AMONG SPANISH-SPEAKING CAREGIVERS OF ENGLISH LEARNERS: AN EXAMINATION OF MODERATORS
}

\author{
LISA FITTON, MS, CCC-SLP ${ }^{1}$, KRISTINA N. BUSTAMANTE, MA, CCC-SLP1, \\ CARLA WOOD, PHD, CCC-SLP ${ }^{1}$ \\ ${ }^{1}$ SCHOOL OF COMMUNICATION SCIENCE \& DISORDERS, FLORIDA STATE UNIVERSITY, TALLAHASSEE, FL, USA
}

\begin{abstract}
The purpose of the present paper was to examine the social validity of telepractice as a service delivery model for Spanishspeaking families of English learners. Quantitative survey methodology was employed to examine 79 caregivers' opinions regarding telepractice and to obtain background information about participants' home environments. Findings revealed that approximately $46 \%$ of the participant sample reported being interested in their children receiving services via telepractice. Caregivers reported limited familiarity with telepractice as an option, but were likely to express interest if their child had an identified speech or language disorder or if they were interested in increased access to Spanish language support for their children. In conclusion, although telepractice is not universally accepted among Spanish-speaking families, it appears to be a promising service delivery model. It is recommended that service providers offer thorough information and address common myths when considering telepractice as a service delivery model for families.
\end{abstract}

Keywords: Bilingualism, Minority language, Telehealth, Telepractice

In the United States, $21 \%$ of school-age children speak a language other than English at home (U.S. Census Bureau, 2015). These children learning English in school are referred to as English language learners or English learners (ELs) and are part of the substantial minority language speaker population observed worldwide (Wiley, Garcia, Danzig, \& Stigler, 2014). In 2012, over $60 \%$ of speechlanguage pathologists in the United States reported having at least one EL on their caseloads (ASHA). As attention to this linguistic minority grows, an increasing number of educators and service providers are encountering barriers that obstruct effective service delivery to ELs. The purpose of the present study was to evaluate the social validity of telepractice, a promising approach proposed to address some of these challenges.

\section{BARRIERS TO HIGH QUALITY SERVICE DELIVERY FOR ELS}

In the United States, there are policies in place designed to mandate culturally and linguistically appropriate services for all children (ASHA, 2016b, IDEA, 2004). However, barriers create challenges to universal implementation of this directive, particularly among minority language speakers. We will review common barriers including gaps in knowledge, linguistic mismatch, distance to bilingual services, and the shortage of bilingual service providers. Many educators and service providers have reported they do not feel they have adequate preparation and training to distinguish the developmental differences between ELs and monolingual language learners, and are less comfortable working with linguistic minorities compared to working with culturally and racially diverse populations (e.g., Bedore \& Peña, 2008; Guiberson \& Atkins, 2012; Jackson, Leacox, \& Callender, 2010).

According to the ASHA Code of Ethics, service providers who feel unqualified to support individuals from different linguistic backgrounds should refer these individuals to other professionals (ASHA, 2016). The rationale for this referral requirement can be found by considering the compounding problems of a linguistic mismatch between professionals and ELs' caregivers, particularly when caregivers have limited English proficiency. Caregiver-professional linguistic differences can lead to decreased caregiver input (Arias \& Morillo-Campbell, 2008) and reduced caregiver knowledge regarding their child's status (Buysse, Castro, West, \& Skinner, 2004). Scheduling appointments, expressing concerns, and obtaining information about their children's therapy are more difficult with linguistic barriers present, and consequently caregivers can become less involved in their children's education (Arias \& Morillo-Campbell, 2008). Given that caregiver involvement in children's academics is critical to 
accurate identification of language impairment and progress in therapy (Justice \& Ezell, 2000; Roberts, Jurgens, \& Burchinal, 2005), poor access to bilingual services can negatively affect child outcomes.

Employing an interpreter is recommended to facilitate communication when a linguistic mismatch occurs and a qualified service provider is not accessible, but this practice does not resolve all the barriers to effective service delivery (ASHA, 2016). Even when interpreters provide open communication between families and providers, knowledge of multilingual language development is necessary to provide appropriate services to ELs. Accurate assessment and effective intervention require familiarity with the impact of (1) low English proficiency, (2) knowledge of another language, and (3) different sociocultural backgrounds on language and literacy acquisition in ELs (Paradis, Genesee, \& Crago, 2011). Limited service provider knowledge can lead to over- or under-identification of ELs as having speech or language impairment (Bedore \& Peña, 2008) and to delayed progress (Kohnert, 2010).

\section{SHORTAGE OF BILINGUAL SERVICE PROVIDERS}

Ideally, clients would be matched with skilled bilingual service providers for efficiency and quality (ASHA, 2016; Kohnert, 2010); however, relative to the number of ELs in the United States, there is a shortage of bilingual speechlanguage pathologists (ASHA, 2012). With limited options for caregivers of ELs who do not have access to bilingual practitioners, families may be asked to drive substantial distances to see bilingual providers or choose to see English-only providers. Because of the high prevalence of poverty among families with low English proficiency (Cosentino de Cohen, Deterding, \& Chu Clewell, 2005), costs related to travel to access services can further inhibit families' participation and access to high quality services (Hernandez, 2004).

\section{ADDRESSING BARRIERS THROUGH TELEPRACTICE}

In response to the limited service delivery options available to linguistically-diverse populations, telepractice has emerged as a promising strategy for increasing access to preferred services (Pham, 2012; Theodoros, 2012; Tucker, 2012). Endorsed by ASHA as an ethical option, telepractice is "the application of telecommunication technology to deliver professional service at a distance by linking clinician to client, or clinician to clinician for assessment, intervention, and/or consultation" (ASHA, n.d.). Through videoconferencing and other continually-evolving technologies, telepractice can offer synchronous interaction when service providers and children are in separate locations.

\section{EVIDENCE-BASED PRACTICE: TELEPRACTICE}

Before adopting telepractice for young ELs, it is necessary to examine external empirical evidence, clinical expertise and expert opinion, and caregiver perspectives as they relate to telepractice (ASHA, n.d.). Telepractice directly addresses accessibility barriers and as a result may be associated with fewer client absences and greater intervention frequency than when services are compared to in-person sessions (Baharav \& Reiser, 2010; Forducey, 2006; Kobak et al., 2011; Vismara, Young, \& Rogers, 2012). However, for telepractice to be considered best practice it must produce satisfactory outcomes with evidence from empirical research, approval of clinical experts, and social validity among caregivers.

Empirically, a growing body of evidence supports the efficacy of telepractice. Emerging research suggests that telepractice and in-person service delivery produce comparable outcomes (e.g., McCullough, 2001; Pham, 2012). In a study designed to compare language assessment conducted in-person to that conducted via telepractice, no significant differences were noted between test scores (Waite, Theodoros, Russell, \& Cahill, 2010). In addition, telepractice has been shown to benefit intervention practice through reduced costs and increased access to services, yielding comparable outcomes to in-person practice (e.g., Grogan-Johnson et al., 2011).

Service providers have generally responded positively to telepractice use (e.g., Tucker, 2012). Reduced absence, continued gains in targeted skills, and increased access to services have been cited as contributors to clinician's acceptance of telepractice (Forducey, 2006; McConnochie et al., 2005; Theodoros, 2012). However, service providers have also identified limitations to widespread telepractice implementation, including concerns regarding technology cost and reliability, lack of physical contact, and reimbursement barriers (Tucker, 2012), suggesting feasibility and acceptance of telepractice is disputable in some areas.

\section{GAPS IN THE LITERATURE}

Information about caregiver perspectives is less widelydocumented than the first two components of evidencebased practice. Several pilot studies suggest that caregivers are satisfied with telepractice after receiving telepractice intervention (Baharav \& Reiser, 2010; Kobak et al., 2011; 
Pham, 2012), but these studies provide only retrospective evidence of family opinions. For service providers who are considering recommending telepractice to caregivers of ELs, the opinions of families with no prior experience with the service delivery model are more beneficial. Critically, families with no prior experience with telepractice may be more likely to be misinformed regarding how this service delivery model is conducted. Lack of information or acceptance of common myths surrounding telepractice (e.g., telepractice is illegal; Geurin, 2009) may influence families' service delivery preferences, making them less likely to want their children to participate in telepractice.

Families' opinions of the service delivery model can directly inform future developments in telepractice-delivered therapy (see Wolf, 1978). Additional examination of both general opinions and potential moderating factors of these opinions is needed to evaluate the social validity of telepractice for Spanish-English speaking children. The motivation for the present study is to help practitioners better understanding the beliefs of ELs' families in order to apply evidence-based practice more comprehensively. The research aims to examine the social validity of telepractice among caregivers of Spanish-speaking ELs in the United States. Spanish-speaking caregivers were focused on because the United States' most populous linguistic minority is Hispanic (U.S. Census, 2014). Furthermore, only $68.4 \%$ of Hispanic individuals ages five and older speak English 'very well' (U.S. Census, 2014). The study was designed to address the following:

1. Is telepractice a socially-valid service delivery model for families of Spanish-English speaking ELs?

2. What factors moderate interest in telepractice for families of Spanish-English speaking ELs?

\section{METHOD}

A survey was constructed to obtain information about telepractice as a service delivery model for caregivers' children. Upon receipt of informed consent, participants completed the survey in their preferred language. To maximize construct validity, the instrument underwent pilot sampling and was then refined based on participant feedback and item analysis. Participants were caregivers of Spanish-speaking children recruited from schools and migrant education programs in northern Florida, Michigan, and Illinois. All procedures were approved by the Human Subjects Committee at Florida State University.

\section{SURVEY PILOT AND REFINEMENT}

The pilot version of the instrument was 17 pages and consisted of 56 items written in both Spanish and English.
Question format included rating scales, yes-no, multiple choice, and open-ended questions to examine the completeness and precision of response by different item types. Questions pertaining to demographics, family language use, and caregiver/child fluency in English and Spanish were included in accordance with best practice for researchers to specify the language dominance of bilingual individuals included in their samples (U.S. Dept. of Education IES WWC, 2013). Caregiver opinions regarding bilingualism, Spanish, and English use were targeted to examine possible relations between telepractice and access to bilingual services (e.g., Pham, 2012). Items focusing on child educational experiences and accessibility to educational services were included to assess general accessibility as a moderator of family interest in telepractice (Forducey, 2006; Vismara et al., 2012). Finally, the survey included questions related to caregiver knowledge and interest in telepractice, and to family's access and competence with technology, which have been cited as common barriers to telepractice implementation (ASHA, n.d.; Geurin, 2009).

Piloting occurred with 34 caregivers who reported speaking primarily Spanish to their children. The participants were recruited using the following eligibility criteria: (a) the participant was the caregiver of at least one child who was between the ages of 0 and 8 years, (b) the participant's child was consistently exposed to some Spanish at home, and (c) the family lived in the United States. Children were not required to have any exposure to English.

The investigators revised the survey in response to pilot participants' responses and individual feedback. Based on item-analysis, investigators retained reliable questions and edited or eliminated questions that may have been confusing or misworded. Refinement from pilot participant feedback focused on: (a) clarity of the wording of the questions; (b) brevity, shortening the questionnaire; and (c) parallelism of questions. Investigators removed unreliable open-ended questions and consolidated parallel questions. Items that were skipped consistently in the pilot were removed (e.g. "What is your child's fluency level for reading in Spanish?").

The final instrument included 37 items and was 10 pages long. The structure of the instrument was similar to that of the pilot instrument, including rating scales, yes-no, multiple choice, and open-ended questions. Content areas were also the same, focusing on demographic information, family language use, fluency in English and Spanish, opinions regarding Spanish and English use, child educational experiences, obstacles encountered in the child's education, knowledge of and interest in telepractice, and access to and competence with technology. There were two versions of the survey, one in Spanish and one in English, to allow participants to respond in their preferred language. Surveys were hand-delivered or mailed to potential participants and included a stamped return envelope. 


\section{ANALYSES}

Descriptive statistics regarding questionnaire response and completion rates were first examined. To reduce the risk of measurement bias related to the construction of the questionnaire, any items that had a missing data rate of $25 \%$ or greater were excluded from subsequent analysis. Descriptives appropriate to the data type, including frequencies, means, and standard deviations, were then obtained for respondent, child, and family characteristics to attain information about the participant sample.

To ascertain the overall social validity of telepractice, frequencies and modes for items targeting caregiver interest in and knowledge of telepractice were examined. Next, to prepare for moderator analyses, composite indices were computed from multiple survey items designed to target the same underlying construct. The construction of these indices was based on prior example of aggregating similar items to represent a single construct (e.g., Montrul, 2012).

To create each composite, all items to be included in the composite were first z-scored to create comparable scaling for the composite (Cohen, Cohen, West, \& Aiken, 2003). The z-scored items were then aggregated through averaging. This approach was selected to reduce the impact of missing data, so that missing responses did not result in skewing of the composite score, and to weight each survey item equally within its composite. The composite indices included: caregiver Spanish fluency, caregiver English fluency, child Spanish fluency, child English fluency, caregiver's value of culture, family access to technology needed to receive telepractice services, caregiver competence with technology needed to receive telepractice services, and parent belief in telepractice myths. The items included in each composite are listed in Table 1.

To identify potential moderators of caregivers' interest in telepractice, bivariate relations between background factors and participants' reported interest in telepractice were examined by obtaining non-parametric correlation coefficients. Although both Kendall's tau and Spearman's rho are both considered acceptable for obtaining nonparametric correlation estimates, Kendall's tau was selected because it generally yields more conservative estimates and is considered more robust to nonnormality (Croux \& Dehon, 2010). To examine relations between dichotomous background variables and reported interest in telepractice more closely, cross tabulation with chi-square testing was also completed. Background factors of interest as potential moderators were: (a) caregiver/child language fluency in English and Spanish (U.S. Dept. of Education IES WWC, 2013); (b) caregiver value of culture (e.g., Pham, 2012); (c) access to and competence with technology (ASHA, n.d.); (d) belief in telepractice myths (Geurin, 2009); and (e) need for telepractice-delivered services, as measured by whether or not the child was diagnosed with a speech or language disorder and caregiver interest in the child receiving Spanish language support (Forducey, 2006; Vismara et al., 2012).

Table 1. Questionnaire Composite Indices

Included Items

\begin{tabular}{|c|c|c|c|c|}
\hline $\begin{array}{l}\text { Caregiver Spanish } \\
\text { Fluency }\end{array}$ & $\begin{array}{l}\text { Listening: Caregiver } \\
\text { Spanish Fluency }\end{array}$ & $\begin{array}{l}\text { Speaking: Caregiver } \\
\text { Spanish Fluency }\end{array}$ & $\begin{array}{l}\text { Reading: Caregiver } \\
\text { Spanish Fluency }\end{array}$ & $\begin{array}{l}\text { Writing: Caregiver } \\
\text { Spanish Fluency }\end{array}$ \\
\hline $\begin{array}{l}\text { Caregiver English } \\
\text { Fluency }\end{array}$ & $\begin{array}{l}\text { Listening: Caregiver } \\
\text { English Fluency }\end{array}$ & $\begin{array}{l}\text { Speaking: Caregiver } \\
\text { English Fluency }\end{array}$ & $\begin{array}{l}\text { Reading: Caregiver } \\
\text { English Fluency }\end{array}$ & $\begin{array}{l}\text { Writing: Caregiver } \\
\text { English Fluency }\end{array}$ \\
\hline $\begin{array}{l}\text { Child Spanish } \\
\text { Fluency }\end{array}$ & $\begin{array}{l}\text { Listening: Child } \\
\text { Spanish Fluency }\end{array}$ & $\begin{array}{l}\text { Speaking: Child } \\
\text { Spanish Fluency }\end{array}$ & & \\
\hline $\begin{array}{l}\text { Child English } \\
\text { Fluency }\end{array}$ & $\begin{array}{l}\text { Listening: Child } \\
\text { English Fluency }\end{array}$ & $\begin{array}{l}\text { Speaking: Child } \\
\text { English Fluency }\end{array}$ & & \\
\hline Value of Culture & $\begin{array}{l}\text { Importance of child } \\
\text { being bilingual }\end{array}$ & $\begin{array}{l}\text { Importance of child } \\
\text { speaking Spanish }\end{array}$ & $\begin{array}{l}\text { Importance of being } \\
\text { bilingual in U.S. }\end{array}$ & \\
\hline $\begin{array}{l}\text { Access to needed } \\
\text { technology }\end{array}$ & $\begin{array}{c}\text { Access to a cordless } \\
\text { phone }\end{array}$ & $\begin{array}{l}\text { Access to a } \\
\text { computer }\end{array}$ & Access to internet & $\begin{array}{l}\text { Access to a web } \\
\text { camera }\end{array}$ \\
\hline $\begin{array}{l}\text { Competence with } \\
\text { needed technology }\end{array}$ & $\begin{array}{l}\text { Competence with a } \\
\text { cordless phone }\end{array}$ & $\begin{array}{l}\text { Competence with a } \\
\text { computer }\end{array}$ & $\begin{array}{l}\text { Competence with } \\
\text { internet }\end{array}$ & $\begin{array}{c}\text { Competence with a } \\
\text { web camera }\end{array}$ \\
\hline $\begin{array}{l}\text { Belief in } \\
\text { Telepractice Myths }\end{array}$ & $\begin{array}{l}\text { No computer-No } \\
\text { telepractice }\end{array}$ & $\begin{array}{l}\text { Child will not pay } \\
\text { attention }\end{array}$ & $\begin{array}{c}\text { Telepractice is lower } \\
\text { quality }\end{array}$ & $\begin{array}{c}\text { Telepractice is not } \\
\text { legal }\end{array}$ \\
\hline
\end{tabular}


Finally, to determine how much of the variability in caregivers' interest in telepractice could be predicted by their other questionnaire responses, multiple logistic regression was conducted. Caregiver report of interest in telepractice was included as the outcome. Background factors were included as predictors in the model only if they were revealed to relate significantly to interest in telepractice during bivariate testing.

\section{RESULTS}

\section{DESCRIPTIVE RESULTS}

Responses from the final instrument were obtained from 79 Spanish-speaking caregivers. Of the 100 surveys hand-delivered by service providers and educators in Florida, 41 were completed. Approximately 125 surveys were delivered by mail to interested individuals in Illinois and Michigan and 20 were mailed back to the investigators. An additional 18 surveys from respondents who declined to report their current state of residence were delivered to the investigators. The overall response rate for the invited individuals was $35.1 \%$.

Of the returned questionnaires, $44.3 \%$ were fully completed. Most participants $(98.7 \%, n=78)$ responded to all demographic questions, and no patterns were observed between demographics and missing data. Four total items had response rates below $75 \%$ and were consequently excluded from subsequent analyses. All four of these items were follow-up questions (e.g., "please explain" following the primary question of "ideally, who would deliver services to your child?") and were not considered central to the content of the questionnaire. Outside of these four items, the most frequently skipped items were the child's date of birth (missing 21.5\%, $n=17$ ) and items designed to examine caregivers' belief in telepractice myths (missing 22.8\%, $n=$ 19). In place of the child's date of birth, most of the caregivers wrote in the child's age. Most participants $(87.3 \%, n=69)$ completed at least $75 \%$ of the questionnaire.

Respondents identified themselves as the parent of an EL in $98.7 \%(n=77)$ of cases. The remaining respondent identified herself as the grandparent of an EL. All respondents reported speaking at least some Spanish at home $(n=76)$ and $32.9 \%(n=25)$ reported also using some English. Over half of families $(67.1 \%, n=51)$ reported Spanish-only home environments. Figure 1 provides the self-reported fluency levels of caregivers and of their children. Of the participants who reported their educational backgrounds, more than half indicated that they did not attend high school. An additional $24 \%$ of caregivers reported starting high school without graduating.

The children identified as ELs were between the ages of 1 year, 9 months to 18 years, with an average age of 7 years, 8 months $(n=74)$. When asked about their children's speech and language development, $27.8 \%(n=22)$ of caregivers indicated that their child had been diagnosed with a speech or language disorder. Of the remaining caregivers, $62.0 \%(n=49)$ reported that their child had no speech or language diagnosis, $5.1 \%(n=4)$ were unsure, and $5.1 \%$ did not respond $(n=4)$. Additional demographic information is reported in Table 2.

Table 2. Family Background Characteristics

\begin{tabular}{|c|c|c|c|c|c|}
\hline Characteristic & $\%$ & $n$ & Characteristic & $\%$ & $n$ \\
\hline \multicolumn{3}{|c|}{ Country of Origin $(n=78)$} & \multicolumn{3}{|c|}{ Child Birthplace $(n=77)$} \\
\hline Mexico & 79.5 & 62 & United States & 90.9 & 70 \\
\hline El Salvador & 12.8 & 10 & $\begin{array}{c}\text { Non-United } \\
\text { States }\end{array}$ & 9.1 & 7 \\
\hline Other & 7.7 & 6 & \multicolumn{3}{|c|}{$\begin{array}{c}\text { Language Child Speaks at } \\
\text { Home }(n=75)\end{array}$} \\
\hline \multicolumn{3}{|c|}{$\begin{array}{l}\text { Geographic Location } \\
\qquad(n=61)\end{array}$} & Spanish & 54.7 & 41 \\
\hline Florida & 67.2 & 41 & $\begin{array}{l}\text { More Spanish } \\
\text { than English }\end{array}$ & 16.0 & 12 \\
\hline Illinois & 21.3 & 13 & $\begin{array}{c}\text { Balanced } \\
\text { Spanish/English }\end{array}$ & 26.7 & 20 \\
\hline Michigan & 9.8 & 6 & $\begin{array}{l}\text { More English } \\
\text { than Spanish }\end{array}$ & 1.3 & 1 \\
\hline Other & 1.6 & 1 & English & 1.3 & 1 \\
\hline \multicolumn{3}{|c|}{$\begin{array}{c}\text { Experience with } \\
\text { Bilingual Services }(n=69)\end{array}$} & \multicolumn{3}{|c|}{$\begin{array}{c}\text { Speech/Language } \\
\text { Disorder Severity }(n=23)\end{array}$} \\
\hline None & 75.4 & 52 & Mild & 30.4 & 7 \\
\hline $\begin{array}{l}\text { Some bilingual } \\
\text { services }\end{array}$ & 24.6 & 17 & Moderate & 60.9 & 14 \\
\hline \multicolumn{3}{|c|}{$\begin{array}{l}\text { Interest Spanish support } \\
\text { for Child? }(n=68)\end{array}$} & $\begin{array}{l}\text { Severe/ } \\
\text { Profound }\end{array}$ & 8.7 & 2 \\
\hline No & 44.1 & 30 & & & \\
\hline Yes & 55.9 & 38 & & & \\
\hline
\end{tabular}




\section{Caregiver Fluency}

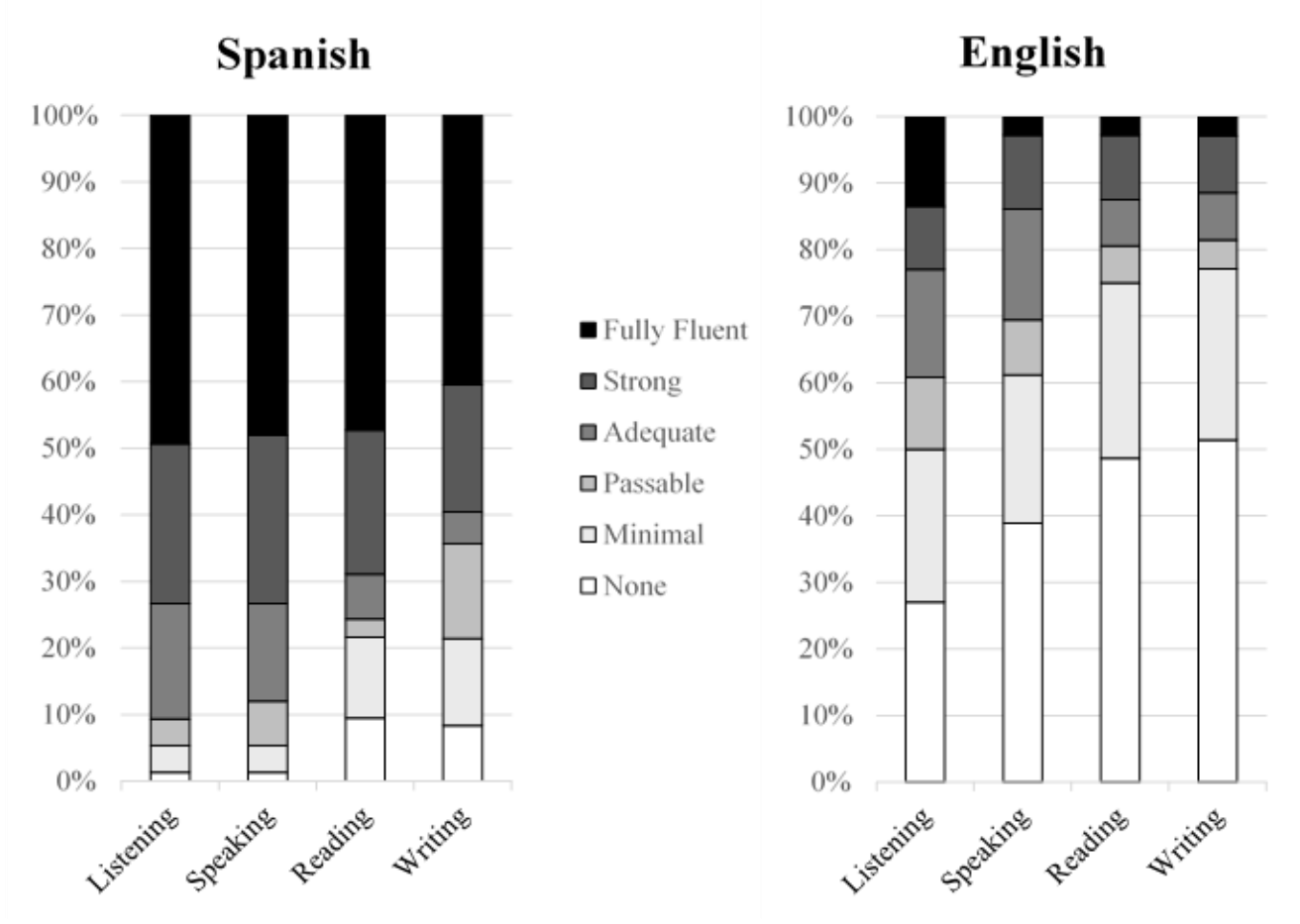

Child Fluency

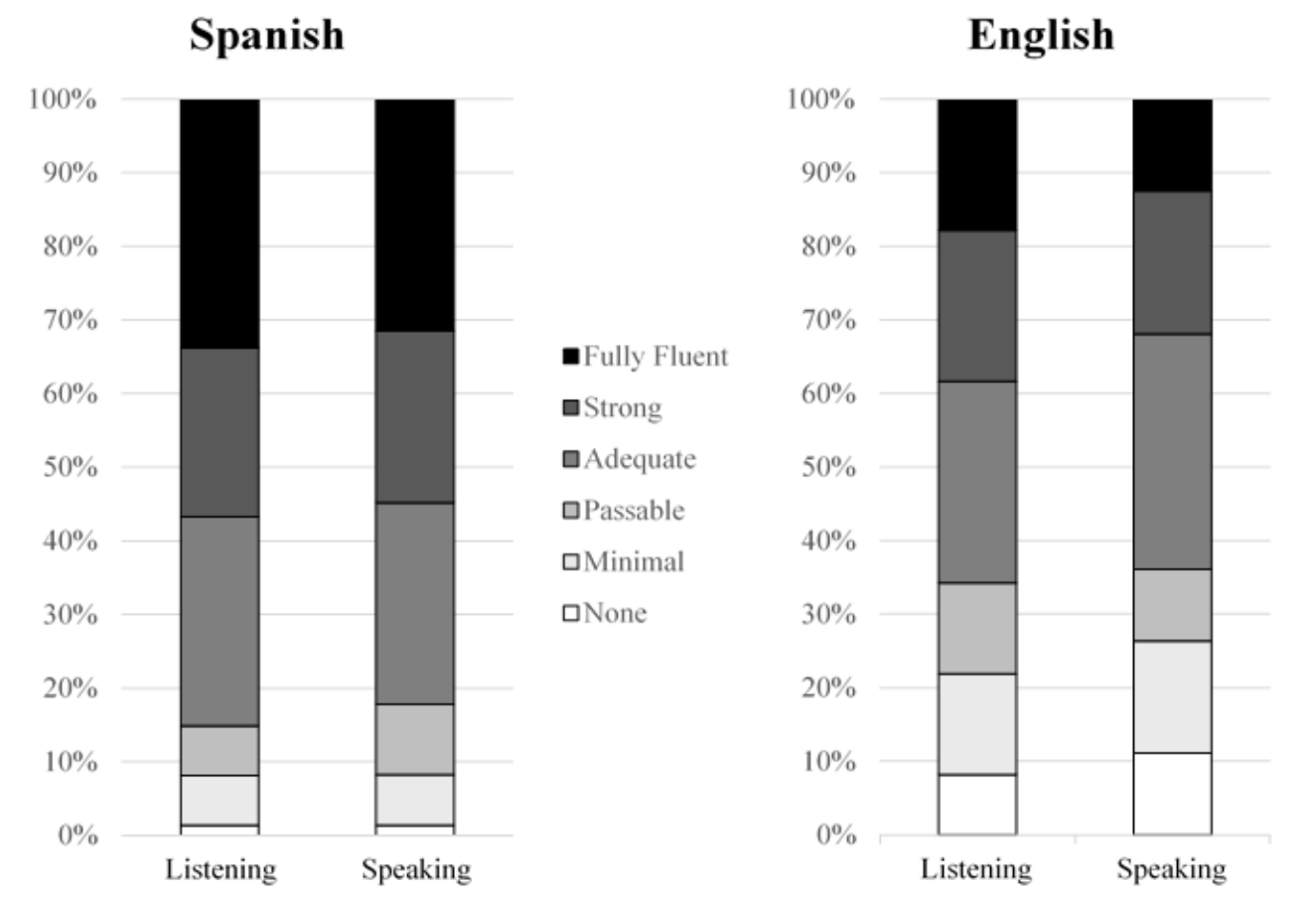

Figure 1. Caregiver and child fluency in English and Spanish. 


\section{SOCIAL VALIDITY OF TELEPRACTICE}

Few participants indicated they had any knowledge of telepractice prior to participation in the study $(3.8 \%, n=3)$. However, given the brief definition of telepractice, $45.6 \%$ ( $n$ $=31$ ) of respondents stated they were interested and $54.4 \%$ ( $n=37)$ stated they were not interested. Participants expressed mixed agreement with each of the telepractice myths (see Figure 2). testing: $\mathrm{X}^{2}(2, n=65)=19.01, p<.001$. Of the 18 caregivers who reported that their child had a speech or language disorder, 16 indicated interest in telepractice. Of the remaining 43 caregivers, 31 indicated they were not interested in telepractice and 12 indicated they would be interested in telepractice service delivery.

Caregivers who were interested in their child receiving Spanish language support were also significantly more interested in telepractice as a service delivery model than those who did not express interest in Spanish support, evidenced by both correlational findings $(\tau=.62 p<.01)$ and cross-tabulation: $\mathrm{x}^{2}(1, n=61)=$ $23.55, p<.001$. Of the 32 families who wanted Spanish language support for their children, 23 reported they would be interested in receiving services via telepractice. Nearly all $(n=26,89.66 \%)$ of the 29 caregivers who were not interested in Spanish language support were similarly uninterested in telepractice.

One post-hoc exploratory test was conducted to examine caregiver report of difficulty accessing services for their child. A cross-tabulation chisquare test revealed a significant difference, $\mathrm{X}^{2}(1, n=62)=25.04$, $p<.001$. Caregivers who reported difficulty obtaining

Figure 2. Caregiver opinions regarding telepractice myths.

\section{MODERATORS OF TELEPRACTICE INTEREST}

Correlational findings revealed that caregiver fluency in English, child fluency in both English and Spanish, caregiver value of culture, family access to and competence with technology, and belief in telepractice myths were not significantly related to reported interest in telepractice. However, caregiver fluency in Spanish, child diagnosis of a speech or language disorder, and caregiver interest in their child receiving Spanish language support were significantly associated with interest in telepractice service delivery. See Table 3 for Kendall's tau correlation coefficients.

Caregivers who reported stronger Spanish fluency levels more commonly reported being interested in telepractice $(\tau=.31, p<.001)$. Those who had children with a diagnosed disorder also expressed interest in telepractice significantly more often than caregivers of children without a speech or language disorder, evidenced by correlational findings $(\tau=.47, p<.001)$ and cross-tabulation chi-square access to services $(n=14)$ unanimously indicated that they would be interested in their child receiving telepractice services.

Multiple logistic regression was conducted to examine how family interest in telepractice was predicted by caregiver fluency in Spanish, child diagnosis of a speech or language disorder, and caregiver interest in their child receiving Spanish language support. A significant overall result was found for the initial three-predictor model $X^{2}(3)=$ $32.78, p<.001$. A pseudo $R^{2}$ value of .604 was obtained, suggesting a moderately strong relation between the predictors and reported interest in telepractice. The Hosmer and Lemeshow Test was not significant $X^{2}(6)=6.00, p=$ .423 , indicating an acceptable model fit. Two of the predictors, however, exhibited evidence of multicollinearity; caregiver fluency in Spanish and caregiver interest in their child receiving Spanish support were significant correlated $(\tau$ $=.31, p=.007$ ) and did not both uniquely contribute to predicting family interest in telepractice services (see Table 4). Because interest in receiving Spanish support was more strongly related to family interest in telepractice than caregiver fluency in Spanish, caregiver Spanish fluency was excluded from the model. 
Table 3. Correlation Coefficients

\begin{tabular}{lllllllllll}
1 & 2 & 3 & 4 & 5 & 6 & 7 & 8 & 9 \\
\hline
\end{tabular}

1. Interest in receiving telepractice

1

2. Caregiver Spanish fluency

$.31^{* *} \quad 1$

$\begin{array}{lllll}\text { 3. Child diagnosis of speech/language disorder } & .47^{\star *} & .06 & 1\end{array}$

$\begin{array}{lllll}\text { 4. Caregiver interest in receiving Spanish support } & .62^{\star \star} & .31^{\star \star} & .36^{\star \star} & 1\end{array}$

$\begin{array}{llllllll}\text { 5. Caregiver English fluency } & -.04 & .04 & .19 & .26^{*} & 1\end{array}$

\begin{tabular}{|c|c|c|c|c|c|c|c|c|c|}
\hline 6. Child Spanish fluency & -.01 & $.42^{\star \star}$ & -.18 & .04 & .01 & 1 & & & \\
\hline 7. Child English fluency & -.22 & -.03 & $-.23^{\star}$ & $-.27^{\star}$ & -.03 & .11 & 1 & & \\
\hline 8. Caregiver value of culture & .03 & $.21^{*}$ & -.09 & -.09 & -.06 & $.24^{\star}$ & .15 & 1 & \\
\hline 9. Access to Technology & .10 & .10 & .20 & .18 & $.32^{\star \star}$ & .08 & .05 & .07 & 1 \\
\hline $\begin{array}{l}\text { 10. Competence with } \\
\text { Technology }\end{array}$ & .12 & .03 & $.25^{\star}$ & .22 & $.37^{\star *}$ & -.11 & -.06 & .04 & $.67^{* *}$ \\
\hline
\end{tabular}

${ }^{*}$ Significant at $p<.05$

${ }^{* *}$ Significant at $p<.01$

Table 4. Logistic Regression Predicting Interest in Telepractice

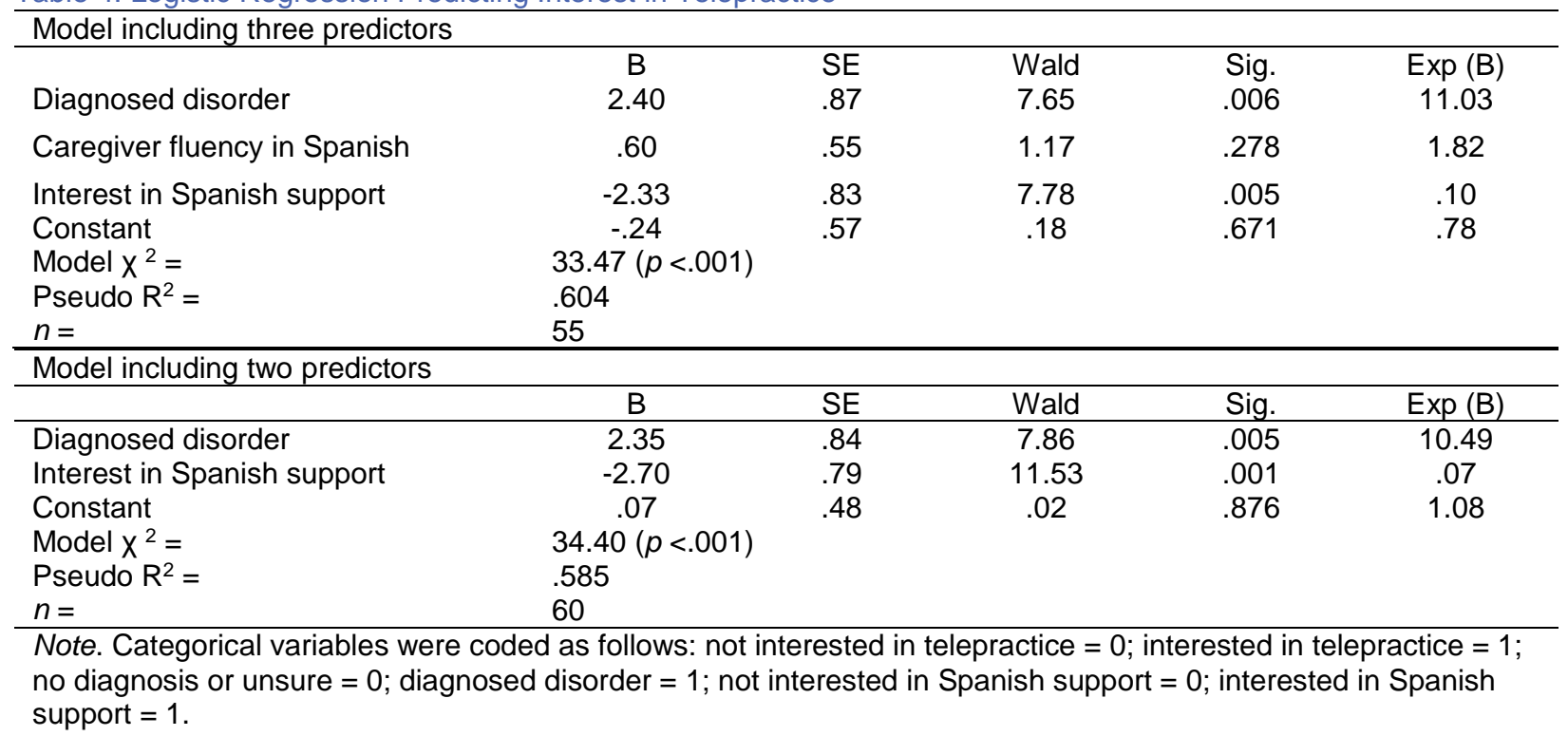


The final model predicting family interest in telepractice included two predictors: child diagnosis of a speech or language disorder and caregiver interest in receiving Spanish language support. The omnibus test of the model was significant $\mathrm{X}^{2}(2)=34.40, p<.001$, and yielded a pseudo $R^{2}$ of .585. The Hosmer and Lemeshow Test for the model was not significant $X^{2}(2)=1.51, p=.471$. Both predictors significantly contributed to the likelihood that caregivers would express interest in telepractice. Families of children who had been diagnosed with a speech or language disorder were more likely to express interest in telepractice services, and those who expressed interest in receiving Spanish language support were also more likely to be interested in telepractice. Both of these predictors uniquely contributed to family interest in telepractice.

\section{DISCUSSION}

The purpose of the present study was to evaluate the social validity of telepractice as a potential service delivery model for Spanish-speaking families of English learners, and to identify moderators of families' interest in telepractice. Quantitative survey methodology was employed to obtain feedback from a diverse sample of Spanish-speaking caregivers of English learners. The survey was designed to elicit caregivers' opinions regarding telepractice as a service delivery model, and to obtain information regarding potential factors relating to families' interest in telepractice as a desired option for their children.

\section{THE SOCIAL VALIDITY OF TELEPRACTICE}

Our findings indicate that Spanish-speaking caregivers' interest in telepractice for their children is currently limited to specific sub-groups of caregivers, which were represented by $46 \%$ of our sample. Over half of the caregivers surveyed indicated that they would not be interested in their child receiving any educational support via telepractice. Although this finding is surprising when considered next to prior work that has suggested telepractice is a positive experience for many Hispanic caregivers (e.g., Vismara et al., 2012), the background characteristics of the present sample offer reasonable explanation. Nearly all caregivers of children with a diagnosed speech or language disorder indicated that they would be interested in telepractice services. Caregivers of children without a diagnosis were divided, with less than a third of these caregivers expressing interest in telepractice. These findings suggest that caregivers are more likely to be interested in unfamiliar service delivery options when their children had a confirmed diagnosis and perhaps motivation based on an immediate need for services, as is the case with ELs with a speech or language disorder. This conclusion was bolstered by evidence that caregivers who had experienced challenges in obtaining appropriate services for their children were more likely to express interest in telepractice than those who did not report difficulty accessing services.

Caregivers who were interested in Spanish language support for their children more frequently reported being interested in telepractice, and reported higher levels of Spanish fluency than caregivers who were not interested in Spanish educational supports. Given the lack of relation between reported English fluency and interest in telepractice, these results suggest that telepractice was perhaps viewed primarily as a vehicle for increasing access to Spanish or bilingual speech and language services, rather than improving access to English services. The majority of the families reported that their children had never received any type of dual language support, despite being English learners, suggesting that the present participant sample generally had limited access to Spanish-speaking service providers.

Some caregivers reported that the limited access to bilingual services they experienced was difficult for them and their children, but others did not consider limited access to dual language services a problem. This finding is indicative of the broad spectrum of beliefs held by Spanishspeaking families. For some participants, maintaining Spanish proficiency was important; for others, achieving high levels of English proficiency was more important. The present research suggests that families' values are critical in determining their preferred form of service delivery; there was a clear distinction between family language preference and the caregivers' openness to telepractice service delivery.

\section{IMPLICATIONS FOR PRACTITIONERS}

Important for clinicians who are considering using telepractice to facilitate increased access to service for families who speak minority languages, most of the survey respondents reported little-to-no prior knowledge of telepractice. This finding suggests that service providers may need to provide informational supports and resources regarding details of the service delivery model when presenting telepractice as an option to families. This point is highlighted by the families' responses to the telepractice myths. Over $30 \%$ of survey respondents indicated that they believed that telepractice service delivery is not possible without owning a personal computer. Even more concerning, less than $20 \%$ of respondents were aware that telepractice is a legal form of service delivery. Given these findings, service providers may need to address these concerns when recommending telepractice to families. It may be beneficial to consider additional informational sharing of resources such as public service announcements or information about options to share at routine doctor's visits or well-child checks. 


\section{IMPLICATIONS FOR RESEARCH}

Despite the small number of participants, the present sample was highly diverse. Families reported a substantial range of Spanish and English use in the home and varying levels of proficiency in each language. These findings lend support to calls for researchers to describe their samples of participants carefully, given the wide range of language environments in ELs' homes. Considering that language exposure has been shown to be a key indicator of children's academic performance (e.g., U.S. Dept. of Education, 2013), obtaining metrics of this exposure would appear to be critical to predicting outcomes accurately. Furthermore, metrics of both child and caregiver proficiency are important because the two are not consistently closely correlated.

\section{CONCLUSIONS}

Results suggest that telepractice is a promising, but not yet widely accepted, service delivery model for young ELs. Families who have experienced barriers to needed services or who expressed interest in supporting their children's Spanish language skills were more likely to be interested in telepractice, despite limited background knowledge about telepractice service delivery. It is recommended that practitioners provide thorough information about telepractice and its associated myths when considering telepractice as a service delivery option for families of ELs, and that practitioners work with families to identify priorities for their child's care.

\section{ACKNOWLEDGEMENTS}

The authors would like to thank the families who participated in this study, particularly those who provided feedback for the development of the final instrument. Special thanks to Dr. Lindsey Leacox and Dr. Maria Pouncey for their support and assistance with the investigation, and to the undergraduate research assistants Joannie Descardes and Alison Dahl for their assistance in entering and coding data. The first author was supported by Predoctoral Interdisciplinary Research Fellowship, funded by the Institute of Education Sciences, U.S. Department of Education (186000-520-025833), and the second author was supported by the Bilingual Oral Language and Literacy Development \& Disorders grant, funded by the U.S. Department of Education Office of Special Education Programs.

\section{REFERENCES}

American Speech-Language Hearing Association. (n.d.). Telepractice. [Practice Portal]. Retrieved May, 2017 from www.asha.org/Practice-Portal/Professional-Issues/Telepractice

American Speech-Language-Hearing Association. (2012). 2012 schools survey. Survey summary report: Number and type of responses, SLPS. Retrieved from http://www.asha.org/uploadedFiles/Schools-2012-SLPFrequencies.pdf

American Speech-Language-Hearing Association. (2016). Code of ethics [Ethics]. Retrieved from http://www.asha.org/Code-ofEthics/

Arias, M.B., \& Morillo-Campbell, M. (2008). Promoting ELL parental involvement: Challenges in contested times (Policy brief). East Lansing, Ml: Great Lakes Center for Education Research and Practice.

Baharav, E., \& Reiser, C. (2010). Using telepractice in parent training in early autism. Telemedicine Journal and E-health, 16(6), 727-731. https://doi.org/10.1089/tmj.2010.0029

Bedore, L. \& Peña, E.D. (2008). Assessment of bilingual children for identification of language impairment: Current findings and implications for practice. International Journal of Bilingual Education and Bilingualism, 11, 1-29. https://doi.org/10.2167/beb392.0

Buysse, V., Castro, D.C., West, T., \& Skinner, M.L. (2004). Addressing the needs of Latino children: A national survey of state administrators of early childhood programs: Executive summary. Chapel Hill: The University of North Carolina, FPG Child Development Institute.

Cohen, J., Cohen, P., West, S. G., \& Aiken, L. S. (2003). Bivariate correlation and regression. Applied multiple regression/correlation analysis for the behavioral sciences ( $3^{\text {rd }}$ ed.) (pp.19 - 63). Mahwah, NJ: Lawrence Erlbaum Associations, Inc.

Cosentino de Cohen, C., Deterding, N., \& Chu Clewell, B. (2005). Who's left behind? Immigrant children in high and low LEP schools (Policy Report). Washington, DC: Urban Institute.

Croux, C., \& Dehon, C. (2010) Influence functions of the Spearman and Kendall correlation measures. Statistical Methods \& Applications, 19(4), 497-515. https://doi.org/10.2139/ssrn.1585216

Forducey, P.G. (2006). Speech telepractice program expands options for rural Oklahoma schools. The ASHA Leader, 11, 12 13. https://doi:10.1044/leader.SCM.11102006.12

Geurin, A. (2009). Get the facts about telepractice. Communicologist: An Official Publication of the Texas SpeechLanguage-Hearing Association, 35(5), 18. Retrieved from http://viperdev3.wyomingnetwork.org/ pdf/Communicologist/10 2009.pdf

Grogan-Johnson, S., Gabel, R., Taylor, J., Rowan, L., Alvares, R., \& Schenker, J. (2011). A pilot exploration of speech sound disorder intervention delivered by telehealth to school-age children. International Journal of Telerehabilitation, 3(1) 31-42. https://doi.org/10.5195/ijt.2011.6064 
Guiberson, M., \& Atkins, J. (2012). Speech-language pathologists' preparation, practices, and perspectives on serving culturally and linguistically diverse children. Communication Disorders Quarterly, 33(3), 169-180.

https://doi.org/10.1177/1525740110384132

Hernandez, D.J. (2004). Demographic change and the life circumstances of immigrant families. Foundation for Child Development, 14(2), 17-47. https://doi.org/10.2307/1602792

Individuals with Disabilities Education Act, 20 U.S.C. § 1400 (2004).

Jackson, C. W., Leacox, L., \& Callender, M. F. (2010). Challenges to early intervention for English language learners: Perceptions of service providers. Early Childhood Services: An Interdisciplinary Journal of Effectiveness, 3(1), 77-97. Retrieved from http://www.pluralpublishing.com/journals ECS.htm

Justice, L. M., \& Ezell, H. K. (2000). Enhancing children's print and word awareness through home-based parent intervention. American Journal of Speech-Language Pathology, 9, 257-269. https://doi.org/10.1044/1058-0360.0903.257

Kobak, K.A., Stone, W.L., Wallace, E., Warren, Z., Swanson, A., \& Robson, K. (2011). A web-based tutorial for parents of young children with autism: Results from a pilot study. Telemedicine Journal and e-health, 17(10), 804-808 https://doi.org/10.1089/tmj.2011.0060

Kohnert, K. (2010). Bilingual children with primary language impairment: Issues, evidence and implications for clinical actions. Journal of Communication Disorders, 43, 456-473. https://doi.org/10.1016/j.jcomdis.2010.02.002

McCullough, A. (2001). Viability and effectiveness of teletherapy for pre-school children with special needs. International Journal of Language and Communication Disorders, 36(Suppl. 1), 321326. https://doi.org/10.3109/13682820109177905

McConnochie, K.M, Wood, N.E., Kitzman, H.J., Herendeen, N.E., Roy, J., \& Roghmann, K.J. (2005). Telemedicine reduces absence resulting from illness in urban child care: Evaluation of an innovation. Pediatrics, 115(5), 1273-

1282. https://doi.org/10.1542/peds.2004-0335

Montrul, S. (2012). Bilingual background questionnaire for Spanish/English speakers. Los Angeles, CA: National Heritage Language Resource Center.

Paradis, J., Genesee, F., \& Crago, M. B. (2011). Dual Language Development and Disorders: A Handbook on Bilingualism and Second Language Learning (2nd Ed). Baltimore, MD: Brookes.

Pew Research Center. (2016). Hispanic trends: Statistical portrait of Hispanics in the United States. Retrieved from http://www.pewhispanic.org/2016/04/19/statistical-portrait-ofhispanics-in-the-united-states-key-charts/
Pham, G. (2012). Addressing less common languages via telepractice: A case example with Vietnamese. Perspectives on Communication Disorders and Sciences in Culturally and Linguistically Diverse Populations, 19(2), 77-83. https://doi.org/10.1044/cds19.3.77

Roberts, J., Jurgens, J., \& Burchinal, M. (2005). The role of home literacy practice in preschool children's language and emergent literacy skills. Journal of Speech, Language, and Hearing Research, 48, 345-359. https://doi.org/10.1044/10924388(2005/024)

Theodoros, D. (2012). A new era in speech-language pathology practice: Innovation and diversification. International Journal of Speech-Language Pathology, 14(3), 189-199. http://dx.doi.org/10.3109/17549507.2011.639390

Tucker, J. K. (2012). Perspectives of speech-language pathologists on the use of telepractice in schools: The qualitative review. International Journal of Telerehabilitation, 4(2), 47-60. https://doi.org/10.5195/iit.2012.6102

U. S. Census Bureau. (2014). FFF Hispanic Heritage Month 2015. Retrieved from https://www.census.gov/newsroom/facts-forfeatures/2015/cb15-ff18.htm

U.S. Census Bureau. (2015). Detailed languages spoken at home and ability to speak English for the population 5 years and over for United States: 2009-2013 [Data file]. Retrieved from https://www.census.gov/data/tables/2013/demo/2009-2013lang-tables.html

U.S. Department of Education, Institute of Education Sciences, What Works Clearinghouse (2013, January). Evidence review protocol for intervention for English language learners, Version 2.2. Retrieved from https://ies.ed.gov/ncee/wwc/Docs/ReferenceResources/wwc e II protocol v2.2.pdf

Vismara, L.A., Young, G.S., \& Rogers, S.J. (2012). Telehealth for expanding the reach of early autism training to parents. Autism Research and Treatment, 2012, 1-12. https://doi.org/10.1155/2012/121878

Waite, M. C., Theodoros, D. G., Russell, T. G., \& Cahill, L. M. (2010). Internet-based telehealth assessment of language using the CELF-4. Language, Speech, and Hearing Services in Schools, 41, 445-458. https://doi.org/10.1044/0161. 1461(2009/08-0131)

Wiley, T. G., Garcia, D. R., Danzig, A. B., \& Stigler, M. L. (2014). Language policy, politics, and diversity in education. Review of Research in Education, 38, vii-xxiii. https://doi.org/10.3102/0091732x13512984

Wolf, M. M. (1978). Social validity: The case for subjective measurement or how applied behavior analysis is finding its heart. Journal of Applied Behavior Analysis, 11, 203-214. https://doi.org/10.1901/jaba.1978.11-203 
This work is licensed under a Creative Commons Attribution 4.0 International License.

This journal is published by the University Library System of the 